\title{
Comparison of Body-Image Dissatisfaction Among Chinese Children and Adolescents at Different Pubertal Development Stages
}

This article was published in the following Dove Press journal: Psychology Research and Behavior Management

\section{Yifei Zhang (D) \\ Ting Li \\ Rongying Yao \\ Hui Han \\ Lu Wu \\ Xuesen Wu \\ Huaiquan Gao \\ Lili Sun \\ Lianguo $\mathrm{Fu}$}

Department of Child and Adolescent Health, School of Public Health, Bengbu Medical College, Bengbu 233030, Anhui, People's Republic of China
Correspondence: Lianguo $\mathrm{Fu}$

Tel +86 I3I95529639

Fax +865523175215

Email lianguofu@I63.com
Background: Body-image dissatisfaction among children and adolescent has become increasingly serious, and may be the result of staged differences in the puberty-development process. The aim of this study was to compare differences in body-image dissatisfaction among children and adolescents at different pubertal stages.

Methods: A total of 574 students aged 8-15 years were recruited from two nine-year schools via stratified cluster sampling, their secondary sex characteristics and external genital development examined, and body-image cognition surveyed using the teenage body-image annoyance questionnaire. This questionnaire covers body-shape, gender, sexual organ, and appearance dissatisfaction. Lower scores indicate a more negative body image.

Results: Total, gender, and appearance-dissatisfaction scores in girls were significantly lower than in boys $(P<0.05)$; however, sexual organ-dissatisfaction scores in girls were significantly higher than in boys $(P<0.05)$. Girls' gender-dissatisfaction scores before breast development Tanner II were higher than those after menarche $(P<0.05)$; however, girls' sexual organ-dissatisfaction scores before breast development Tanner II were significantly higher than those after menarche $(P<0.05)$.

Conclusion: The girls were more dissatisfied with their gender and appearance than the boys, and the boys were more dissatisfied with their sexual organs than the girls. The girls were more dissatisfied with their sexual organs before breast development Tanner II and more dissatisfied with their gender after menarche.

Keywords: body image, self-perception, puberty, development, children, adolescents

\section{Background}

"Body image" refers to the multifaceted psychological experience of embodiment, especially but not exclusively one's physical appearance, ${ }^{1}$ and includes not only accurate judgment of one's own body shape and size but also body-related feelings, thoughts, and behavior. ${ }^{2}$ Body-image dissatisfaction is a psychological symptom caused by a disappointing self-image, due to a perception of one's own body deviating from an ideal body image, while body-image disorder is a symptom of mental disorder caused by real physical defects. ${ }^{3}$ Body-image dissatisfaction has been the most common cognitive problem related to body image among children and adolescents, and includes such issues as dissatisfaction with body shape, gender, sexual organs, and appearance. ${ }^{4}$ In many countries, the proportion of children and adolescents with body dissatisfaction has increased. ${ }^{5,6} \mathrm{Fu}$ et al showed that $67.3 \%$ of Chinese children were dissatisfied with their body shape, with $35.1 \%$ 
of them desiring to be thinner and $32.2 \%$ of them desiring to be heavier. ${ }^{7}$ Studies have shown significant associations between body-image dissatisfaction and low self-esteem, depression, and eating disorders. ${ }^{8,9}$ Kim et al reported that body-image dissatisfaction was an important factor to contributing suicide ideation among Korean teenagers. ${ }^{10}$ In addition, adolescents with more dissatisfaction with their bodies might be at an increased risk of developing hypertension, diabetes, and other chronic diseases. ${ }^{11}$ Ackard et al found that adolescent girls who were overweight may cause weight dissatisfaction and eating disorders. ${ }^{12}$ With the rapid spread of childhood obesity in the world, especially in developed countries, body-image dissatisfaction has become an important psychological health issue. ${ }^{13,14}$

Puberty is an important stage ranging from childhood to adulthood, with characteristics including rapid growth in body height and weight, gradual development of secondary sexual characteristics, and enhancement of sexual maturity. ${ }^{15}$ Adolescent boys are often focused on exercising to build strength and muscles, ${ }^{16}$ and they tend to care more about other's opinions than their own. Adolescent girls prefer to compare their bodies and appearances with their peers and are also curious about the opposite sex. A study showed that early-maturing boys were most satisfied with their weight; however, early-maturing girls were most dissatisfied with their weight. ${ }^{17}$ Blyth et al reported that early versus late onset of menarche had different effects on certain aspects of satisfaction with body image, depending on the school environment. ${ }^{18}$ In addition, girls are more likely to be influenced by media campaigns, such as television, the Internet, and film/television stars, which result in negative body-image perception. ${ }^{19}$

It has long been well known that puberty is a continuous and staged development process. There are evident differences in physical and psychological developments among the different stages of pubertal development. ${ }^{20,21}$ With continuous changes in body growth and psychological development, there may be different levels of body-image dissatisfaction among different pubertal development stages. The purpose of this study was to compare differences in body-image dissatisfaction among children and adolescents with different pubertal development stages and provide guidance for targeted intervention measures for negative adolescent body image.

\section{Methods}

\section{Participants}

Students aged 8-15 years were recruited from two 9-year schools via stratified cluster sampling, stratified by grade, and clustered by class. A total of 574 students were surveyed: 305 boys and 269 girls. Exclusion criteria were students with endocrine disease, central nervous system disease, drug-induced secondary obesity, family history of mental disorders, taking psychotropic substances for $>8$ weeks, physical disabilities, and other chronic diseases. Inclusion criteria were permanent residence and agreement to sign informed consent.

\section{Puberty Development}

Participants were accompanied by their guardians to the physical examination center of a grade A class-three hospital. Secondary sex characteristics and external genital development of students were examined by sex-matched physicians. Girls were checked for breast development based on Tanner staging and asked whether menarche had occurred (yes or no). Boys had their testicular volume measured using a Prader testicular volume meter and asked whether first spermatorrhea had occurred (yes or no). Pubertal development in girls and boys was divided into three stages: stage I (boys, testicular volume $<4 \mathrm{~mL}$; girls, breast development $<$ Tanner stage II [in stage I, children are characterized mainly by body-shape growth]), stage II (boys, testicular volume $\geq 4 \mathrm{~mL}$ and no spermatorrhea; girls, breast development $\geq$ Tanner stage II and no menarche [in stage II, adolescent secondary sexual characteristics and sexual organs begin to develop]), and stage III (boys, after spermatorrhea; girls, aftermenarche [in stage III, adolescent secondary sexual characteristics and sexual organs reach adult level]). ${ }^{20-22}$

\section{Body-Image Dissatisfaction}

Body image dissatisfaction was surveyed using the teenage body-image annoyance questionnaire (TBIAQ), composed of four cognitive dimensions: body shape dissatisfaction, gender dissatisfaction, sexual organ dissatisfaction, and appearance dissatisfaction. ${ }^{4}$ There are 25 items/questions in the TBIAQ, with eight, four, four, and nine questions assessing body shape-, gender-, sexual organ-, and appearancedissatisfaction dimensions, respectively. For example, item 1 states "I think I am overweight or obese", and the answer is assigned a maximum of three points: 1 for "yes", 2 for "incomplete yes", and 3 for "no". Lower points indicate a more negative body image. In this study, the $\alpha$-coefficient for the TBIAQ was 0.889 , with values of $0.766,0.590,0.701$, and 0.875 for body shape-, gender-, sexual organ-, and appearance-dissatisfaction dimensions, respectively. The $\alpha$ coefficients of total, body shape, gender, sexual organ, and appearance dimensions in boys were $0.897,0.775,0.517$, 
0.742 , and 0.880 , respectively, and in girls $0.878,0.754$, $0.624,0.615$, and 0.867 , respectively.

\section{Statistical Analysis}

SPSS 22.0 software was used to analyse the data. Means \pm SD were used to describe quantitative data and proportions for enumeration data. Student's $t$-test and one-way ANOVA (multiple comparisons using the LSD $t$-test) were used to analyze differences in body-image dissatisfaction. Multiple linear regression was used to analyze associations between development stages and body-image dissatisfaction after adjusting for BMI, all of which were statistically significant at $P<0.05$.

\section{Results}

As shown in Table 1, total, gender-, and appearance-dissatisfaction scores in girls were significantly lower than in boys (Cohen's $d$-values were 0.211, 0.398, and 0.229, respectively; $P<0.05$ ); however, the sexual organ-dissatisfaction scores in girls were significantly higher than in boys ( $d=0.187, P<0.05)$. There were no significant differences in body shape-dissatisfaction scores, BMI, or age between sexes $(P>0.05)$. As shown in Figure 1, the proportion of boys who had had their first spermatorrhea was $12.5 \%$ (43 of 305$)-66.7 \%$ (10 of 16) among 14-year-old boys. Meanwhile, the proportion of girls with menarche was $43.1 \%$ (116 of 269) and $66.7 \%$ (20 of 30) among 12 year-old girls. The proportion of boys with testicular volume $<4 \mathrm{~mL}$ was $48.2 \%$ (147 of 305 ). The proportion of girls with breast development at Tanner I was 25\% (67 of 269).

As shown in Table 2, there were no significant differences in the four dimensions or the total body imagedissatisfaction scores between boys with testicular volume $<4 \mathrm{~mL}$ and those with testicular volume $\geq 4 \mathrm{~mL}$ or between boys with first spermatorrhea and those without $(P>0.05)$. As shown in Table 3, gender-dissatisfaction scores in girls with breast development at Tanner stage I and without menarche were significantly higher than scores in girls with breast development $\geq$ Tanner stage II and menarche, respectively (Cohen's $d=0.341$ and 0.377 , respectively; $P<0.05$ ); however, sexual organ-dissatisfaction scores in girls with breast development at Tanner stage I and without menarche were significantly lower than in girls with breast development $\geq$ Tanner stage II and occurrence of menarche $(d=0.282$ and 0.347 , respectively; $P<0.05)$, respectively. In addition, there were no significant differences in body-shape, appearance-, or total dissatisfaction scores between girls with breast development at Tanner stage I and those with breast development at $\geq$ Tanner stage II or between girls without menarche and those with menarche $(P>0.05)$.

As shown in Table 4, the results of the one-way ANOVA showed that there were no significant differences in the four dimensions or the total dissatisfaction scores among boys at three developmental stages $(P>0.05)$. In addition, there were no significant differences in bodyshape, appearance-, or total dissatisfaction scores among girls at the three developmental stages $(P>0.05)$. However, girls' gender-dissatisfaction scores at stage I and stage II were higher than in stage III $\left(\eta^{2}=3.8 \%, P<0.05\right)$, and there was still a significant association between developmentstage and gender-dissatisfaction scores after adjusting for BMI $\left(\beta \pm \mathrm{SE}-0.458 \pm 0.142, R^{2}=0.038 ; P<0.01\right)$. In contrast, girls' sexual organ-dissatisfaction scores in stage I were significantly higher than in stage II and stage III, respectively $\left(\eta^{2}=4.4 \%, P<0.05\right)$, and there was still a significant association between development stage and sexual organ--dissatisfaction scores after adjusting for BMI $(\beta \pm$ SE 0.340 \pm 0.098$\left.), R^{2}=0.043 ; P<0.01\right)$.

\section{Discussion}

The results of the present study showed that there were significant differences in total, gender-, and appearance-

Table I Comparisons of Body Image-Dissatisfaction Scores and Ages Between Boys and Girls (Means \pm SD)

\begin{tabular}{|l|l|l|l|l|l|}
\hline & Boys (n=305) & Girls (n=269) & t-value & P-value & Cohen's d \\
\hline Age (years) & $11.46 \pm 1.77$ & $11.67 \pm 1.75$ & 1.46 & 0.144 & 0.119 \\
BMI & $19.61 \pm 3.77$ & $19.82 \pm 5.25$ & 0.54 & 0.588 & 0.046 \\
Body shape & $18.48 \pm 3.94$ & $17.98 \pm 3.74$ & 1.54 & 0.125 & 0.130 \\
Gender & $9.51 \pm 1.66$ & $8.80 \pm 1.90$ & 4.77 & $<0.001$ & 0.398 \\
Sexual organs & $10.76 \pm 1.76$ & $11.05 \pm 1.31$ & 2.24 & 0.026 & 0.187 \\
Appearance & $22.99 \pm 4.32$ & $22.00 \pm 4.32$ & 2.72 & 0.007 & 0.229 \\
Total & $61.74 \pm 9.35$ & $59.84 \pm 8.69$ & 2.53 & 0.012 & 0.211 \\
\hline
\end{tabular}



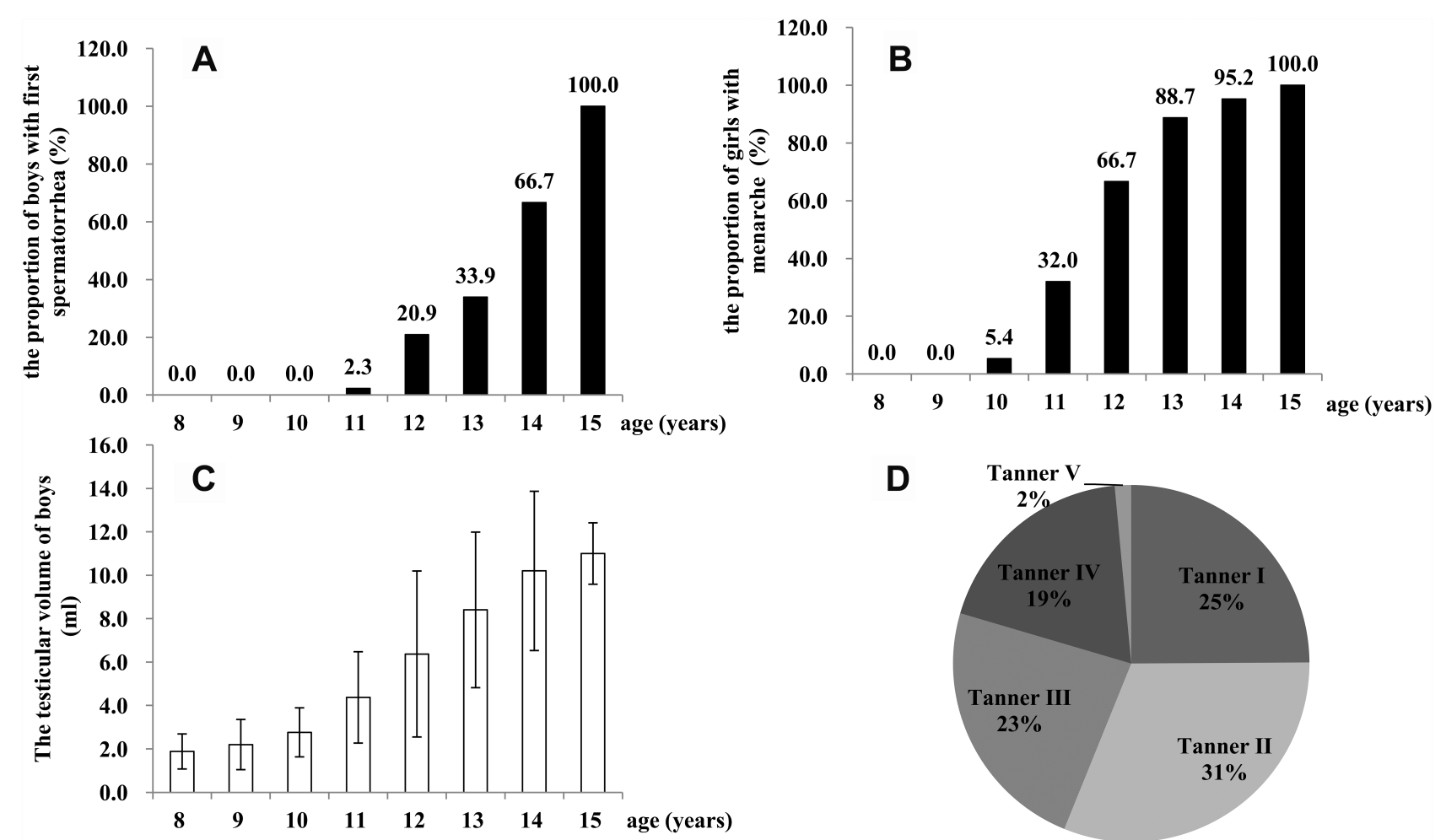

Figure I Status of pubertal development among boys and girls. (A) Proportion of boys with spermatorrhea; (B) proportion of girls with menarche; (C) testicular volume of boys; (D) proportion of breast-development Tanner stages.

dissatisfaction scores between boys and girls based on the TBIAQ, which indicated that girls were more dissatisfied with their gender and appearance (with medium effect values). Previous studies have shown that girls are more dissatisfied with their bodies than boys, especially in terms of gender and appearance. ${ }^{23-25}$ One reason might be that the ideology of being thin, which signifies beauty in Western societies, has influenced the body-image mentalities of Chinese adolescents. With the popularization of the Internet and portable mobile devices in recent years, the ideology of being thin has become widely spread among children and adolescents. ${ }^{26}$ Research has also shown that girls often share pictures of slender bodies obtained from the Internet or other media and discuss with their peers about how to achieve these types of bodies. ${ }^{27}$ This deviation from an ideal figure might affect their perceptions of their bodies, especially in girls with lower self-esteem. ${ }^{28}$ The present research supported the strength of the cultural ideal of thinness for adolescent women, which influenced their perception of body image. ${ }^{17}$ Yang et al showed that adolescent girls were more sensitive to negative stimuli than boys. ${ }^{29}$ In addition, girls preferred to compare their appearances with their peers more than boys. The other reason why girls are more dissatisfied with their body

Table 2 Comparisons of Body Image-Dissatisfaction Scores Among Boys with Different Testicular Volume and First Occurrence of Spermatorrhea (Means \pm SD)

\begin{tabular}{|c|c|c|c|c|c|c|c|c|c|c|}
\hline \multirow{2}{*}{$\begin{array}{l}\text { TBIAQ } \\
\text { Dimensions }\end{array}$} & \multicolumn{2}{|c|}{ Testicular Volume } & \multirow[t]{2}{*}{$t$-value } & \multirow[t]{2}{*}{$P$-value } & \multirow[t]{2}{*}{ Cohen's d } & \multicolumn{2}{|c|}{ First Spermatorrhea } & \multirow[t]{2}{*}{ t-value } & \multirow[t]{2}{*}{$P$-value } & \multirow[t]{2}{*}{ Cohen's d } \\
\hline & $\begin{array}{l}<4 \mathrm{~mL} \\
(\mathrm{n}=\mid 47)\end{array}$ & $\begin{array}{l}\geq 4 \mathrm{~mL} \\
(\mathrm{n}=\mid 58)\end{array}$ & & & & $\begin{array}{l}\text { No } \\
(n=262)\end{array}$ & $\begin{array}{l}\text { Yes } \\
(n=43)\end{array}$ & & & \\
\hline Total & $61.93 \pm 10.23$ & $61.57 \pm 8.48$ & 0.33 & $0.74 I$ & 0.038 & $61.72 \pm 9.63$ & $61.88 \pm 7.49$ & 0.11 & 0.914 & 0.019 \\
\hline Body shape & $18.64 \pm 4.07$ & $18.32 \pm 3.82$ & 0.70 & 0.484 & 0.081 & $18.50 \pm 4.04$ & $18.33 \pm 3.29$ & 0.27 & 0.788 & 0.046 \\
\hline Gender & $9.43 \pm 1.85$ & $9.59 \pm 1.48$ & 0.83 & 0.406 & 0.096 & $9.50 \pm 1.70$ & $9.60 \pm 1.43$ & 0.40 & 0.693 & 0.064 \\
\hline Sexual organs & $10.78 \pm 1.91$ & $10.75 \pm 1.62$ & 0.11 & 0.912 & 0.017 & $10.7 \mid \pm 1.83$ & $11.07 \pm 1.28$ & 1.58 & 0.119 & 0.228 \\
\hline Appearance & $23.08 \pm 4.63$ & $22.91 \pm 4.03$ & 0.36 & 0.722 & 0.039 & $23.0 \mathrm{I} \pm 4.44$ & $22.88 \pm 3.55$ & 0.17 & 0.862 & 0.032 \\
\hline
\end{tabular}


Table 3 Comparisons of Body Image-Dissatisfaction Scores Among Girls with Different Breast-Development Stages and Menarche (Means \pm SD)

\begin{tabular}{|c|c|c|c|c|c|c|c|c|c|c|}
\hline \multirow[t]{2}{*}{$\begin{array}{l}\text { TBIAQ } \\
\text { Dimensions }\end{array}$} & \multicolumn{2}{|c|}{$\begin{array}{l}\text { Breast-Development } \\
\text { Tanner Stage }\end{array}$} & \multirow[t]{2}{*}{ t-value } & \multirow[t]{2}{*}{$P$-value } & \multirow[t]{2}{*}{ Cohen's d } & \multicolumn{2}{|l|}{ Menarche } & \multirow[t]{2}{*}{$t$-value } & \multirow[t]{2}{*}{$P$-value } & \multirow[t]{2}{*}{ Cohen's d } \\
\hline & II $(n=67)$ & $\begin{array}{l}\geq I I \\
(n=202)\end{array}$ & & & & $\begin{array}{l}\text { No } \\
(n=153)\end{array}$ & $\begin{array}{l}\text { Yes } \\
(n=\mid 16)\end{array}$ & & & \\
\hline Total & $59.64 \pm 9.37$ & $59.90 \pm 8.48$ & 0.21 & 0.833 & 0.029 & $59.94 \pm 9.38$ & $59.70 \pm 7.72$ & 0.23 & 0.816 & 0.028 \\
\hline Body shape & $17.94 \pm 3.64$ & $18.00 \pm 3.78$ & 0.10 & 0.918 & 0.016 & $18.01 \pm 3.79$ & $17.95 \pm 3.69$ & 0.13 & 0.900 & 0.016 \\
\hline Gender & $9.27 \pm 1.77$ & $8.64 \pm 1.92$ & 2.37 & 0.018 & $0.34 I$ & $9.10 \pm 1.80$ & $8.39 \pm 1.96$ & 3.11 & 0.002 & 0.377 \\
\hline Sexual organs & $10.61 \pm 1.73$ & $11.20 \pm 1.11$ & 2.60 & 0.011 & 0.282 & $10.86 \pm 1.47$ & $11.30 \pm 1.03$ & 2.88 & 0.004 & 0.347 \\
\hline Appearance & $21.82 \pm 4.82$ & $22.07 \pm 4.15$ & 0.41 & 0.684 & 0.056 & $21.97 \pm 4.57$ & $22.06 \pm 3.99$ & 0.18 & 0.862 & 0.021 \\
\hline
\end{tabular}

Table 4 Comparison of Body Image-Dissatisfaction Scores Among Different Pubertal Stages (Means \pm SD)

\begin{tabular}{|c|c|c|c|c|c|c|}
\hline TBIAQ Dimensions & Stage I & Stage II & Stage III & $F$-value & $P$-value & $\eta^{2}$ \\
\hline \multicolumn{7}{|l|}{ Boys } \\
\hline Total & $61.93 \pm 10.23$ & $61.45 \pm 8.85$ & $61.88 \pm 7.49$ & 0.088 & 0.916 & $<0.001$ \\
\hline Body shape & $18.64 \pm 4.07$ & $|8.32 \pm 4.0|$ & $18.33 \pm 3.29$ & 0.245 & 0.783 & 0.002 \\
\hline Gender & $9.43 \pm 1.85$ & $9.58 \pm 1.50$ & $9.60 \pm 1.43$ & 0.353 & 0.703 & 0.002 \\
\hline Sexual organs & $10.78 \pm 1.91$ & $10.63 \pm 1.72$ & $11.07 \pm 1.28$ & 0.960 & 0.384 & $<0.001$ \\
\hline Appearance & $23.08 \pm 4.63$ & $22.91 \pm 4.21$ & $22.88 \pm 3.55$ & 0.064 & 0.938 & $<0.001$ \\
\hline \multicolumn{7}{|l|}{ Girls } \\
\hline Total & $59.64 \pm 9.37$ & $60.17 \pm 9.44$ & $59.70 \pm 7.72$ & 0.096 & 0.909 & $<0.001$ \\
\hline Body shape & $17.94 \pm 3.64$ & $18.06 \pm 3.93$ & $17.95 \pm 3.69$ & 0.026 & 0.974 & $<0.001$ \\
\hline Gender & $9.27 \pm 1.77$ & $8.98 \pm 1.81$ & $8.39 \pm 1.96^{\mathrm{a}}$ & 5.301 & 0.006 & 0.038 \\
\hline Sexual organs & $10.61 \pm 1.73$ & $11.06 \pm 1.20^{\mathrm{a}}$ & $11.30 \pm 1.03^{\mathrm{a}}$ & 6.067 & 0.003 & 0.044 \\
\hline Appearance & $21.82 \pm 4.82$ & $22.08 \pm 4.39$ & $22.06 \pm 3.99$ & 0.083 & 0.920 & $<0.001$ \\
\hline
\end{tabular}

Note: ${ }^{a} P<0.01$ compared with stage I.

image than boys might be that Chinese parents are stricter with girls and more tolerant with boys. ${ }^{30,31}$ The present study showed that sexual organ dissatisfaction scores in girls were significantly higher than in boys, which indicated that boys paid more attention to the development of their sexual organs and more frequently talked about sexual organs with their peers than girls. The frequent communication between boys may be the reason for the boys' higher dissatisfaction with their sex organs compared to that of girls.

It has long known that there are continuous and staged development processes of puberty in children and adolescents. For example, the development of breasts to Tanner stage II in girls and testicular volume to $4 \mathrm{~mL}$ in boys indicates the beginning of pubertal development. The occurrence of menarche in girls and first spermatorrhea in boys are markers of sexual maturity. In the present study, the sampled children and adolescents were divided into three pubertydevelopment stages, which were based on Tanner stage II breast development and occurrence of menarche in girls and testicular volume $\geq 4 \mathrm{~mL}$ and first occurrence of spermatorrhea in boys. ${ }^{20-22}$ The most important feature of adolescents in stage I is the rapid development of the physique. In addition to this rapid physique development, ability to generalize and reason gradually begin to develop in stage II, and abstract thinking and analytical skills develop further as well. ${ }^{32}$ In stage III, social and cultural factors and interest in the opposite sex might play important roles in body-image dissatisfaction.

However, the results of the present study showed that there were no significant differences in total, body-shape, gender, sexual organ, or body image-dissatisfaction scores among boys at stage I, stage II, and stage III. A study in Brazilian boys showed that the rate of body-image dissatisfaction decreased during adolescent development. ${ }^{33}$ The reason for this result might be decreased body-fat accumulation and an increased muscle mass accompanied by growth and development processes in boys. ${ }^{34}$ The results 
of the present study showed that body-shape and appearance-dissatisfaction scores were not significantly different among girls during the different stages. Previous research has also shown that girls' perceptions of appearance do not change with age. ${ }^{35}$

The present study showed a decreasing tendency of gender-dissatisfaction scores (3.8\% of effect value) and an increasing tendency of sexual organ-dissatisfaction scores (4.4\% of effect value) from stage I to stage II in girls, which indicated that increased gender dissatisfaction was present in late puberty and that increased sexual organ dissatisfaction was present in early puberty. From the results of the present and previous studies, girls were more dissatisfied with their gender than boys. Family members, such as parents, grandfathers, and grandmothers, might play a significant role in gender dissatisfaction in girls during puberty development. ${ }^{36}$ The girls were able to recognize their gender based on physiological characteristics before breast development Tanner II; however, they had no realistic abstract thinking of their gender based on social characteristics. Therefore, gender dissatisfaction could directly reflect dissatisfaction with sexual organs in girls with stage I. With developments in abstract thinking and analytical skills, the girls with menarche would gradually accept the reality of their female sexual organs and understand the social characteristics of their gender, which would result in these girls becoming more dissatisfied with their gender than girls at stage I and stage II. In addition, the teenagers were less influenced by their parents and more influenced by peer-to-peer interactions and social media. ${ }^{37,38}$

There are still several limitations in the current study. The puberty-development stages were defined based on cross-sectional data, which could not determine causal links. In addition, the results were based on the TBIAQ scale fitted to Chinese children and adolescents, which limits comparison of our results with those from other studies. The $\alpha$-coefficient of gender dimensions on the TBIAQ was low. Also, it is not clear if other factors, such as BMI or cultural beauty ideals, play a mediating effect.

\section{Conclusion}

The findings of the present study showed that the girls were more dissatisfied with their gender and appearance than boys and boys more dissatisfied with their sexual organs than girls. The girls were more dissatisfied with their sexual organs before breast development Tanner II and were more dissatisfied with their gender after menarche.

\section{Abbreviation}

TBIAQ, teenage body-image annoyance questionnaire.

\section{Data-Sharing Statement}

The data collected and analyzed during the current study are available from the corresponding author on reasonable request.

\section{Ethics Approval and Consent to Participate}

This study was approved by the Medical Ethics Committee of Bengbu Medical College (2015; 003), and the students' parents signed informed consent before physical measurements were completed. This study was conducted in accordance with the Declaration of Helsinki.

\section{Acknowledgments}

The authors would like to thank the children and adolescents who participated in the current study, and thank Weige Jiang and Yu Liu for giving assistance in the survey.

\section{Author Contributions}

All authors made substantial contributions to conception and design, acquisition of data, or analysis and interpretation of data, took part in drafting the article or revising it critically for important intellectual content, gave final approval of the version to be published, and agree to be accountable for all aspects of the work.

\section{Funding}

This work was supported by the National Natural Science Foundation of China (81502823), University Natural Science Research Project of Anhui province (KJ2019A0298), Innovation Team of Health Information Management and Application Research of Bengbu Medical College (BYKC201913), and Bengbu Medical College Scientific and Innovation Research for Graduate Students (BYYCX1854).

\section{Disclosure}

The authors declare that they have no competing interests.

\section{References}

1. Cash TF. Body image: past, present, and future. Body Image. 2004;1 (1):1-5. doi:10.1016/S1740-1445(03)00011-1

2. Neves CM, Cipriani FM, Meireles JFF, Morgado F, Ferreira MEC. Body image in childhood: an integrative literature review. Rev Paul Pediatr. 2017;35(3):331-339. doi:10.1590/1984-0462/;2017;35;3;00 002 
3. Lu LG, Chen TN, Chen JG, Lin WG. A self rating scale of body image. Chin Mental Health J. 2000;14(5):299-302.

4. Gao YB, Peng WB, Zhou LH, Luo BW, Ye LH. Reliability and validity of body image depression questionnaire for teenagers. Chin $J$ Sch Health. 2005;26(12):1005-1006.

5. Baskova M, Holubcikova J, Baska T. Body-image dissatisfaction and weight-control behaviour in Slovak adolescents. Cent Eur J Public Health. 2017;25(3):216-221. doi:10.21101/cejph.a4724

6. Juli MR. Perception of body image in early adolescence. An investigation in secondary schools. Psychiatr Danub. 2017;29(Suppl 3):409-415.

7. Fu LG, Wang HJ, Li XH, Yang YD, Sun LL, Ma J. Analysis on the correlation of body image dissatisfaction and body shape parameters among children and adolescents. Chin J Child Heal Care. 2014;22 (11):1174-1178.

8. Lewer M, Bauer A, Hartmann AS, Vocks S. Different facets of body image disturbance in binge eating disorder: a review. Nutrients. 2017;9(12):1294. doi:10.3390/nu9121294

9. Esser P, Mehnert A, Johansen C, Hornemann B, Dietz A, Ernst J. Body image mediates the effect of cancer-related stigmatization on depression: a new target for intervention. Psychooncology. 2018;27 (1):193-198. doi:10.1002/pon.4494

10. Kim DS. Body image dissatisfaction as an important contributor to suicidal ideation in Korean adolescents: gender difference and mediation of parent and peer relationships. J Psychosom Res. 2009;66 (4):297-303.

11. Pinquart M. Body image of children and adolescents with chronic illness: a meta-analytic comparison with healthy peers. Body Image. 2013;10(2):141-148. doi:10.1016/j.bodyim.2012.10.008

12. Ackard DM, CB P. Association between puberty and disordered eating, body image, and other psychological variables. Int $J$ Eat Disord. 2001;29(2):187-194. doi:10.1002/1098-108X(200103) 29:2<187::AID-EAT1008>3.0.CO;2-R

13. Bucchianeri MM, Arikian AJ, Hannan PJ, Eisenberg ME, NeumarkSztainer D. Body dissatisfaction from adolescence to young adulthood: findings from a 10-year longitudinal study. Body Image 2013;10(1):1-7. doi:10.1016/j.bodyim.2012.09.001

14. Eisenberg ME, Neumark-Sztainer D, Paxton SJ. Five-year change in body satisfaction among adolescents. J Psychosom Res. 2006;61 (4):521-527. doi:10.1016/j.jpsychores.2006.05.007

15. Christian P, Smith ER. Adolescent undernutrition: global burden, physiology, and nutritional risks. Ann Nutr Metab. 2018;72(4):316328. doi:10.1159/000488865

16. Stanford JN, McCabe MP. Sociocultural influences on adolescent boys' body image and body change strategies. Body Image. 2005;2 (2):105-113. doi:10.1016/j.bodyim.2005.03.002

17. Blyth DA, Simmons RG, DF Z. Satisfaction with body image for early adolescent females: the impact of pubertal timing within different school environments. J Youth Adolesc. 1985;14(3):207-225. doi:10.1007/BF02090319

18. Duncan PD, Ritter PL, Dornbusch SM, Gross RT, MC J. The effects of pubertal timing on body image, school behavior, and deviance. $J$ Youth Adolesc. 1985;14(3):227-235. doi:10.1007/BF02090320

19. Dallesasse SL, Kluck AS. Reality television and the muscular male ideal. Body Image. 2013;10(3):309-315. doi:10.1016/j.bodyim.20 13.02.004

20. Marshall WA, Tanner JM. Variations in pattern of pubertal changes in girls. Arch Dis Child. 1969;44(235):291-303. doi:10.1136/ adc.44.235.291

21. Marshall WA, Tanner JM. Variations in the pattern of pubertal changes in boys. Arch Dis Child. 1970;45(239):13-23. doi:10.1136/ adc. 45.239 .13
22. Tanner JM, RH W. Clinical longitudinal standards for height, weight, height velocity, weight velocity, and stages of puberty. Arch Dis Child. 1976;51(3):170-179. doi:10.1136/adc.51.3.170

23. van Vliet JS, Gustafsson PA, Duchen K, Nelson N. Social inequality and age-specific gender differences in overweight and perception of overweight among Swedish children and adolescents: a cross-sectional study. BMC Public Health. 2015;15:628. doi:10.1186/s12889015-1985-x

24. Michael SL, Wentzel K, Elliott MN, et al. Parental and peer factors associated with body image discrepancy among fifth-grade boys and girls. J Youth Adolesc. 2014;43(1):15-29. doi:10.1007/s10964-0129899-8

25. Gillen MM, Lefkowitz ES. Gender and racial/ethnic differences in body image development among college students. Body Image. 2012;9(1):126-130. doi:10.1016/j.bodyim.2011.09.004

26. Crone EA, Konijn EA. Media use and brain development during adolescence. Nat Commun. 2018;9(1):588. doi:10.1038/s41467-01803126-x

27. Veldhuis J, Konijn EA, Seidell JC. Weight information labels on media models reduce body dissatisfaction in adolescent girls. $J$ Adolesc Health. 2012;50(6):600-606. doi:10.1016/j.jadohealth.2011. 10.249

28. van der Meulen M, Veldhuis J, Braams BR, Peters S, Konijn EA, Crone EA. Brain activation upon ideal-body media exposure and peer feedback in late adolescent girls. Cogn Affect Behav Neurosci. 2017;17(4):712-723. doi:10.3758/s13415-017-0507-y

29. Yang J, Zhang S, Lou Y, et al. The increased sex differences in susceptibility to emotional stimuli during adolescence: an eventrelated potential study. Front Hum Neurosci. 2017;11:660. doi:10.3389/fnhum.2017.00660

30. Basu S, Zuo X, Lou C, Acharya R, Lundgren R. Learning to be gendered: gender socialization in early adolescence among Urban Poor in Delhi, India, and Shanghai, China. J Adolesc Health. 2017;61(4S):S24-S29. doi:10.1016/j.jadohealth.2017.03.012

31. Zuo X, Lou C, Gao E, Cheng Y, Niu H, Zabin LS. Gender differences in adolescent premarital sexual permissiveness in three Asian cities: effects of gender-role attitudes. J Adolesc Health. 2012;50(3 Suppl): S18-S25. doi:10.1016/j.jadohealth.2011.12.001

32. Brown KA, Patel DR, Darmawan D. Participation in sports in relation to adolescent growth and development. Transl Pediatr. 2017;6 (3):150-159. doi:10.21037/tp.2017.04.03

33. Miranda VP, Conti MA, de Carvalho PH, Bastos RR, Ferreira ME. Body image in different periods of adolescence. Rev Paul Pediatr. 2014;32(1):63-69. doi:10.1590/S0103-05822014000100011

34. Castro IR, Levy RB, Cardoso Lde O, et al. Body image, nutritional status and practices for weight control among Brazilian adolescents. Cien Saude Colet. 2010;15(Suppl 2):3099-3108. doi:10.1590/S141381232010000800014

35. Craike M, Young JA, Symons CM, et al. Trends in body image of adolescent females in metropolitan and non-metropolitan regions: a longitudinal study. BMC Public Health. 2016;16(1):1143. doi:10.1186/s12889-016-3815-1

36. Piaget J. Intellectual evaluation from adolescence to adulthood. Hum Dev. 1972;15:1-12. doi:10.1159/000271225

37. Sherman LE, Payton AA, Hernandez LM, Greenfield PM, Dapretto $M$. The power of the like in adolescence: effects of peer influence on neural and behavioral responses to social media. Psychol Sci. 2016;27(7):1027-1035. doi:10.1177/0956797616645673

38. Sherman LE, Greenfield PM, Hernandez LM, Dapretto M. Peer influence via instagram: effects on brain and behavior in adolescence and young adulthood. Child Dev. 2018;89(1):37-47. doi:10.1111/ cdev. 12838 


\section{Publish your work in this journal}

Psychology Research and Behavior Management is an international, peer-reviewed, open access journal focusing on the science of psychology and its application in behavior management to develop improved outcomes in the clinical, educational, sports and business arenas. Specific topics covered in the journal include: Neuroscience, memory and decision making; Behavior modification and management; Clinical

applications; Business and sports performance management; Social and developmental studies; Animal studies. The manuscript management system is completely online and includes a very quick and fair peer-review system, which is all easy to use. Visit http://www. dovepress.com/testimonials.php to read real quotes from published authors.

Submit your manuscript here: https://www.dovepress.com/psychology-research-and-behavior-management-journal 